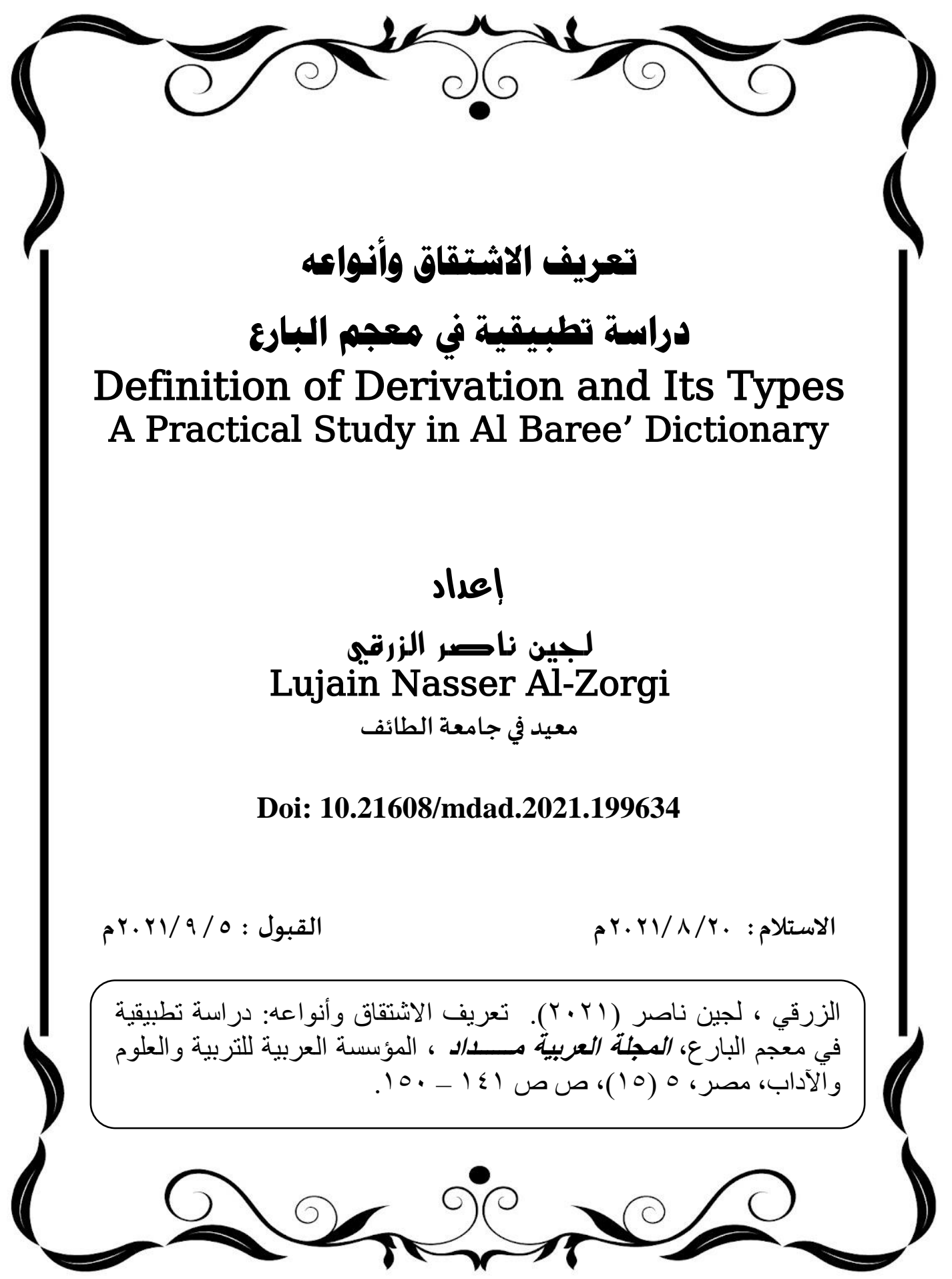




\section{تعريف الاشتقاق وأنواعه: دراسة تطبيقية في معجم البارع}

يهدف هذا البحث إلى معرفة أنواع الاشتقاق الواردة في معجم البارع في اللغة، وقد

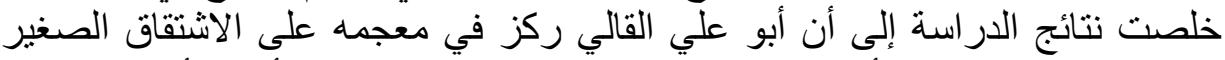

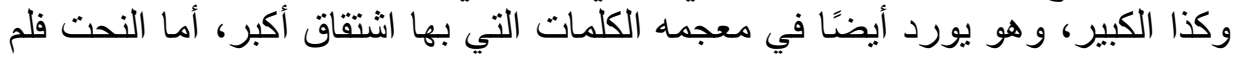

\section{Abstract:}

يتطرق إليه القالي في معجمه ورده

This research aims to know the types of derivations contained in the dictionary of Al-Baree' in language, and the results of the study concluded that Abu Ali Al-Qali focused in his dictionary on small and large derivations, and he also mentioned words that have a greater derivation, while sculpture did not mention it.

\section{مُ}

يؤكد المستشرقون في أبحاثهم بأن من أبرز سمات اللغات السامية الاشتقاق، ولقد تنبه

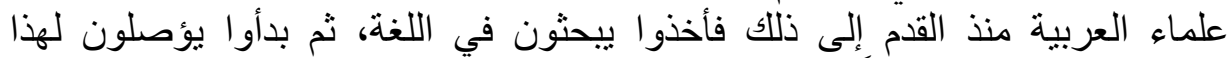

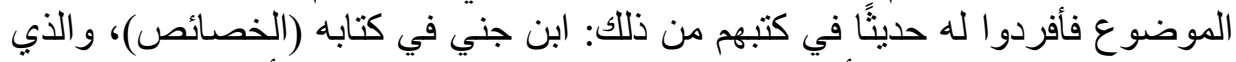

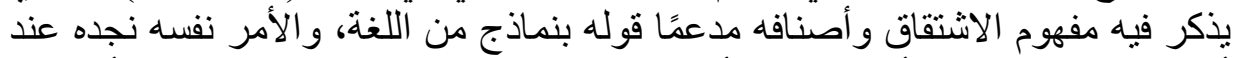

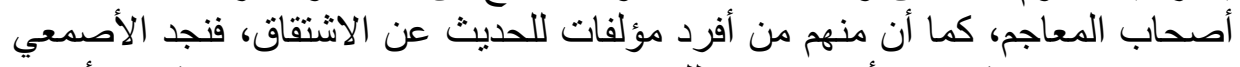

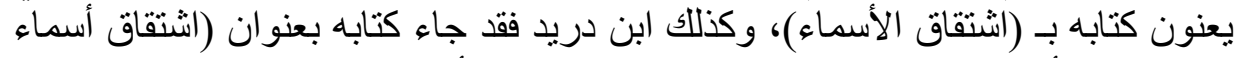

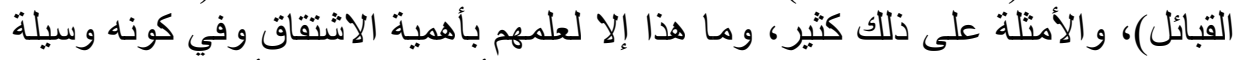

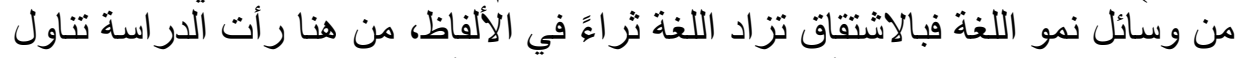

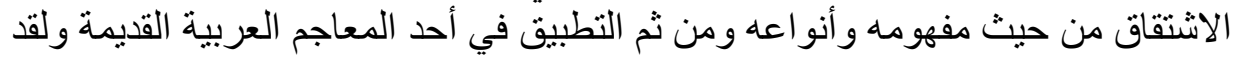

ويكمن الهدف من بحثي (تعريف الاشتثاق والبـ وأنواعه: دراسة تطبيقية في معجم وقع الاختيار على معجم البار ع.

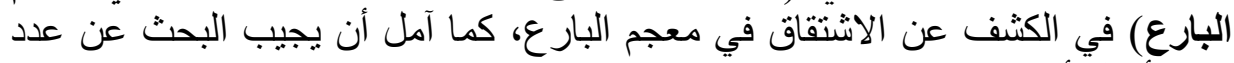
من الأسئلة أهمها: البكار

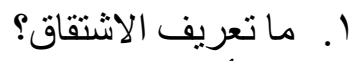

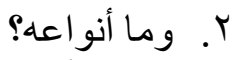

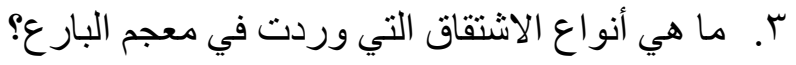




\section{أهمية الموضوع وأسباب اختياره:}

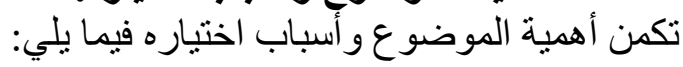

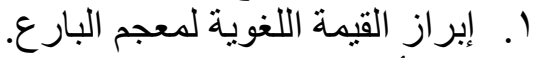

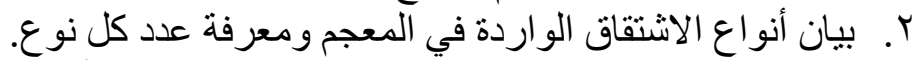

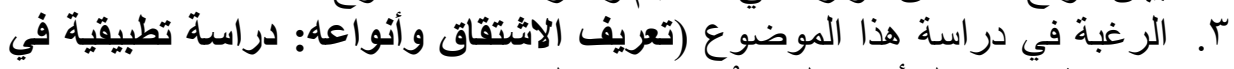

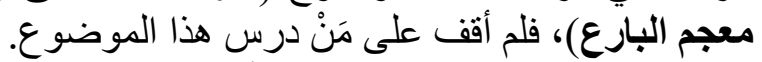
وقد اقتضت دراسة هذا الموضوع البارع أن تشتمل على مقدمة، ومبحثين، وخاتمة تليها

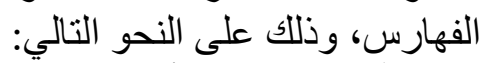
المقدمة: فتشمل على أهداف البحث، وذلى وأهميته، و أسباب اختياره، وخطة البحث.

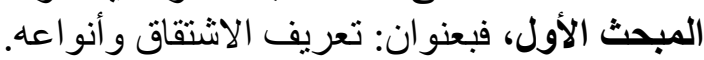

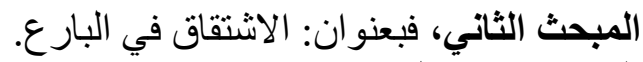

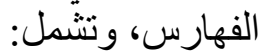
فهرس المصنادر و والمر اجع. فهرس الموضو عات.

المبحث الأول: تعريف الاشتثقاث وأنواعه

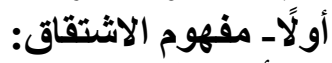

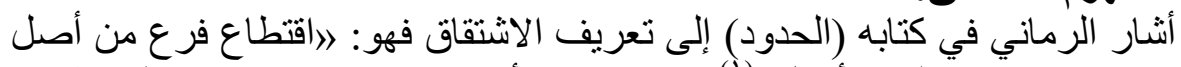

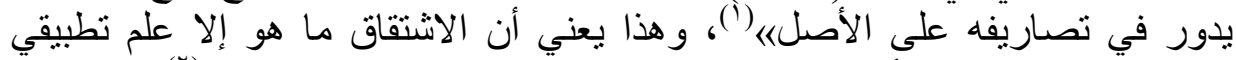

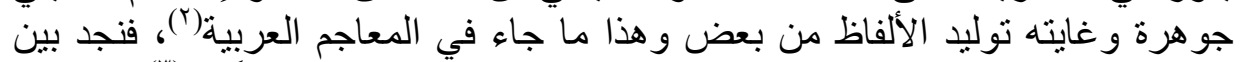

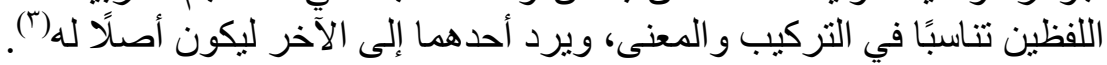

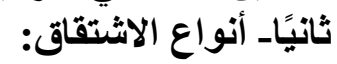

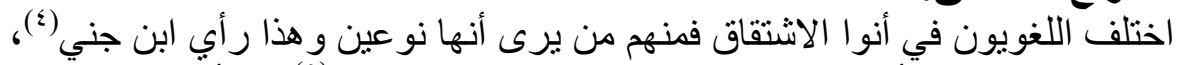

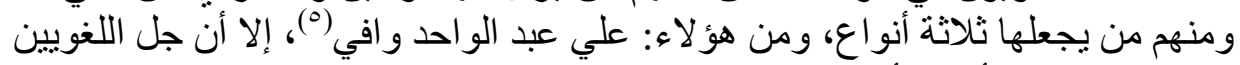

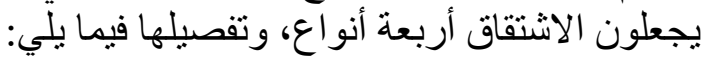

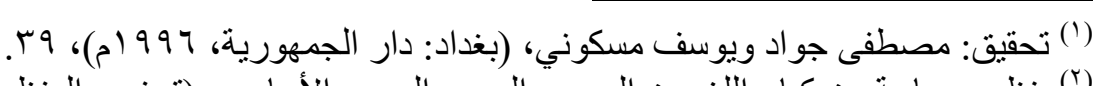

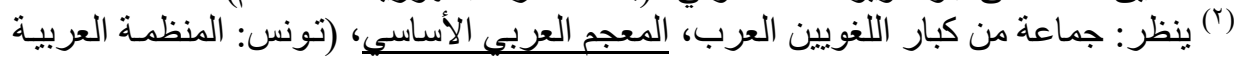

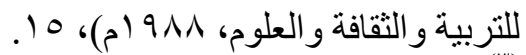

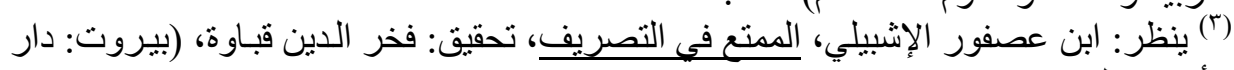

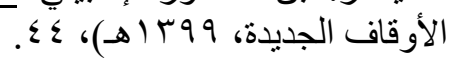

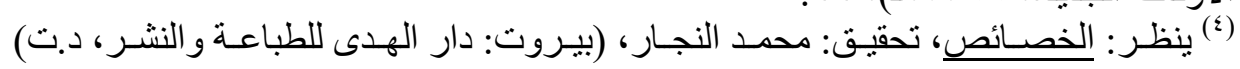
. $1 \mathrm{M} / \mathrm{T}$

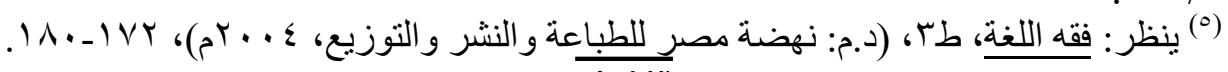
$1 \leq \Gamma$ 


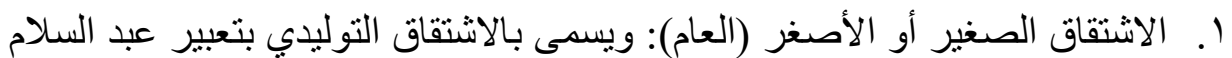

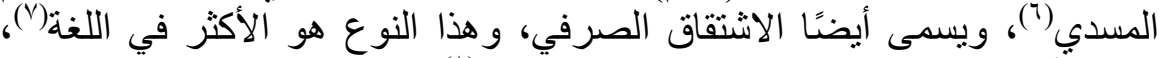

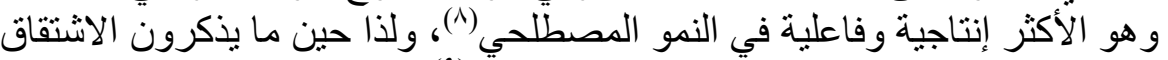

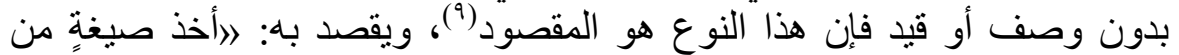

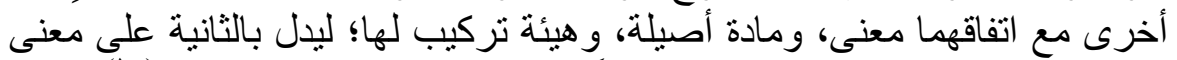

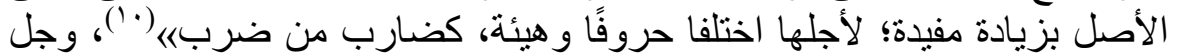

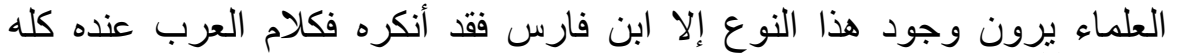

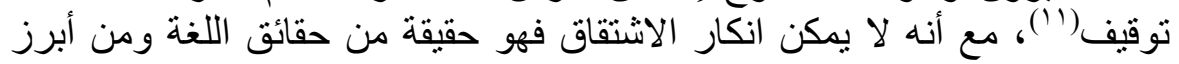

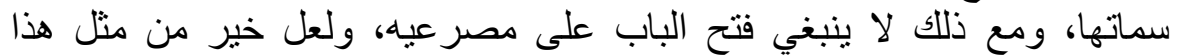

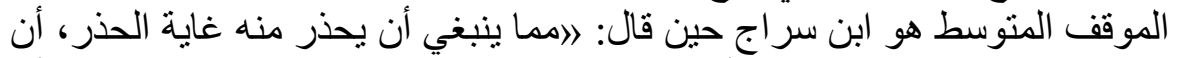

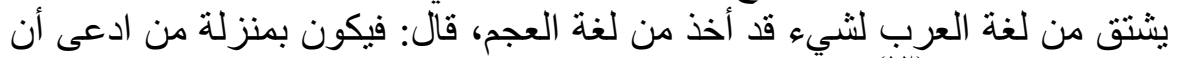

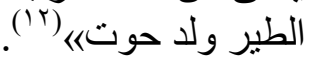

r. الاشتقاق الكبير (القلب): ويعرفه ابن جني: الأن تأخذ أصلًا من الأصول الثناثية،

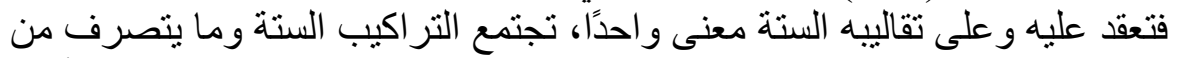

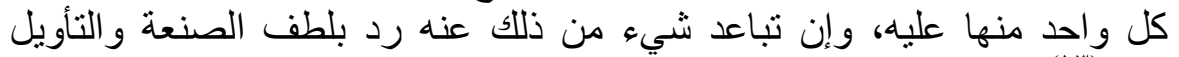

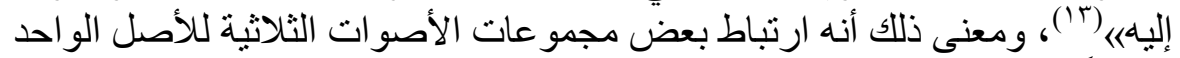

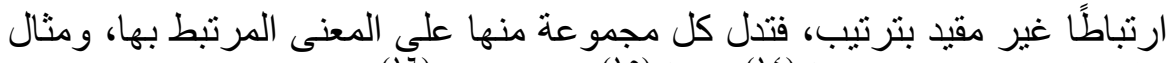

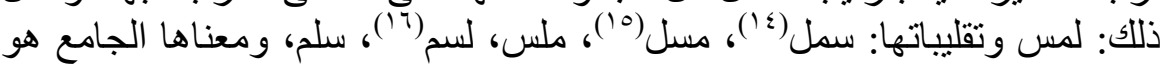

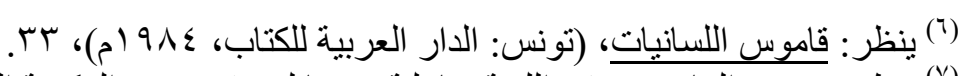

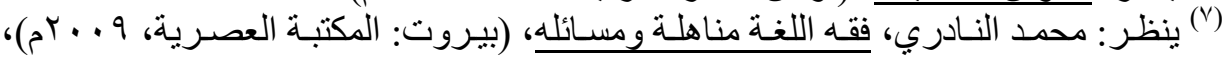
(^) بنظر : علي القاسمي، مقدمة في علم المصطلح، ط؟، (القاهرة: مكتبـة النهضـة المصرية،

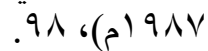
(9) ينظر : محمد صديق خان، العلم الخفاق من علم الاشتقاق، (القسطنطينية: مطبعة الجو انب،

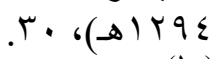

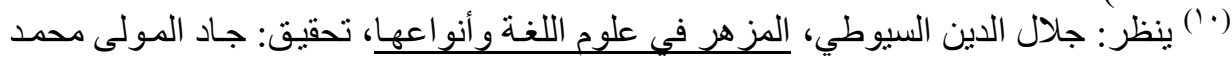

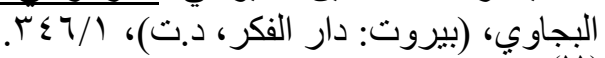

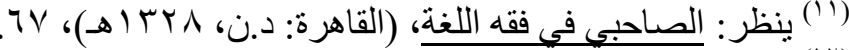

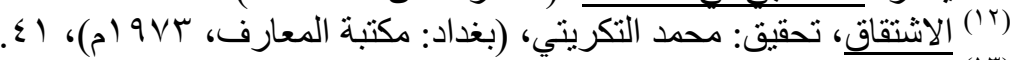

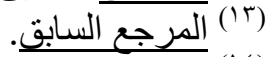

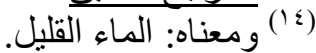

$$
\begin{aligned}
& \text { (10) ومعناها: ما يجري فئه المعاء. } \\
& \text { (17) (1) (1) ومعناه: الالتصاق. يجري }
\end{aligned}
$$




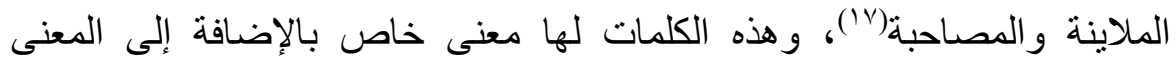

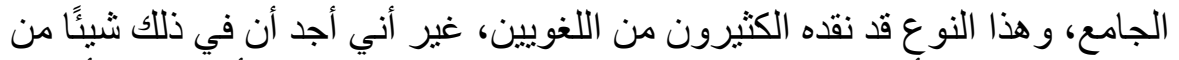

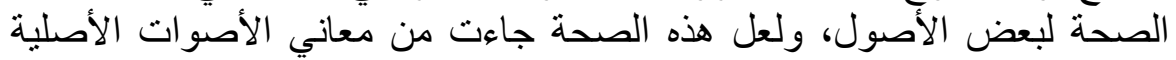

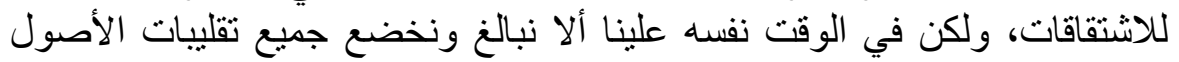

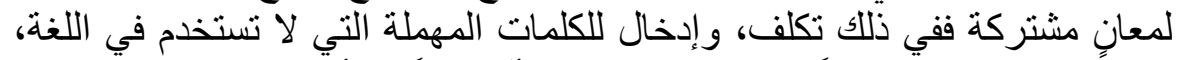

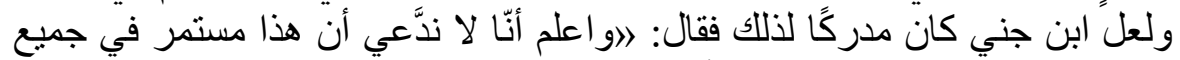

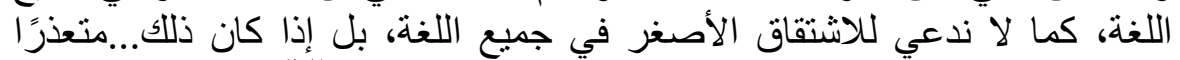

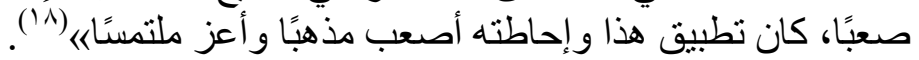

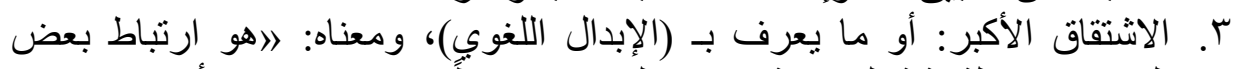

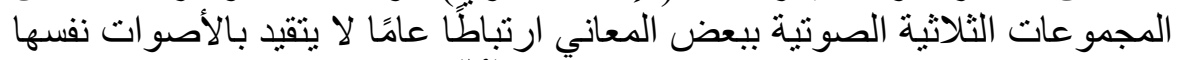

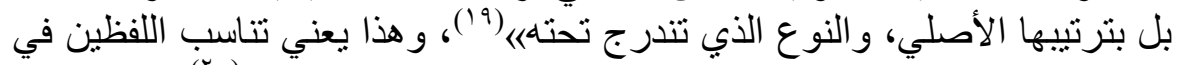

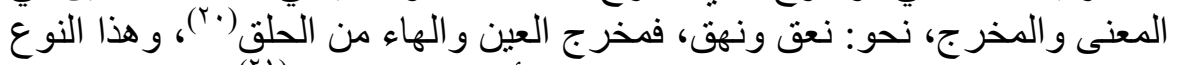

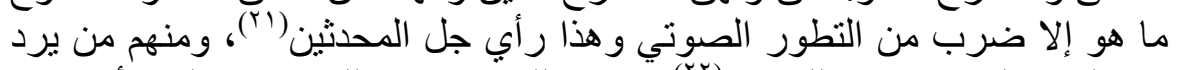

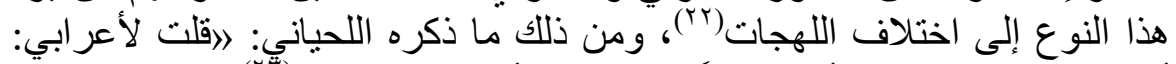

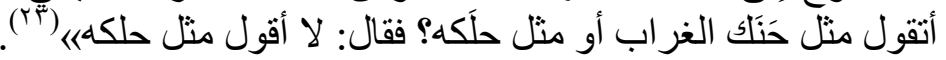

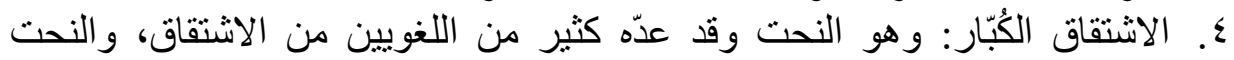

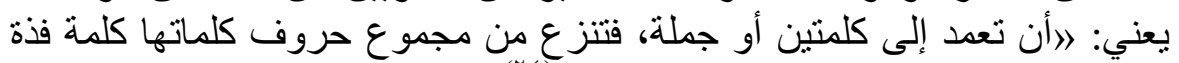

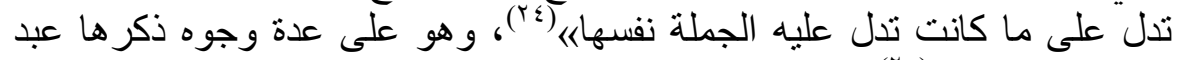

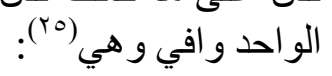
النحت من الجملة، نحو: قولن إلنا بسمل وتعني: بسم الله الرحمن الرحيم، وكذا حوقل وتعني: لا حول ولا قوة إلا بالله. النحت من العلم المركب تركيبًا إضافيَّا، نحو : عبشمى وير اد به: عبد شمس، و أيضًا:

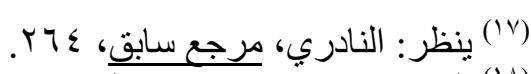

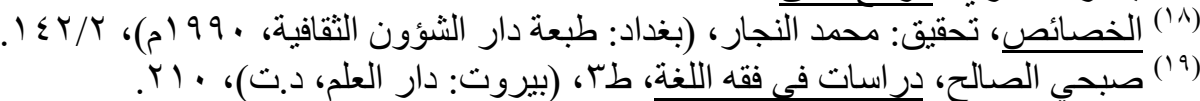

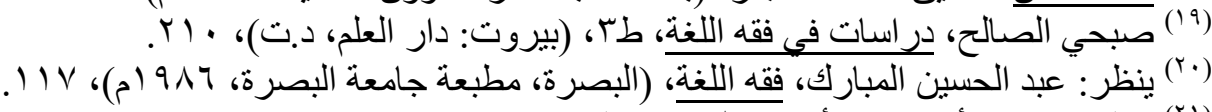

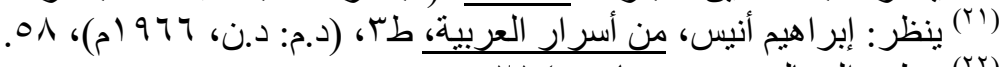

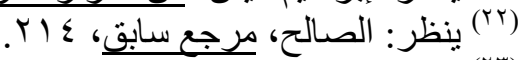

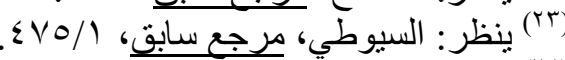

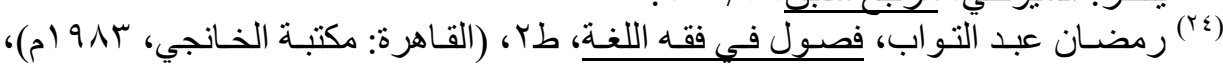

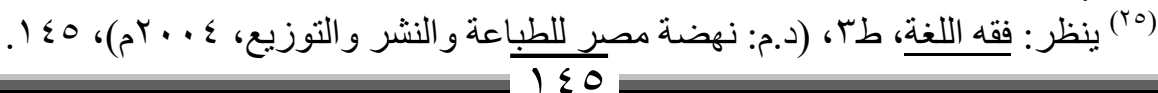




$$
\text { مرقسى وير اد به: امرؤ القيس. }
$$

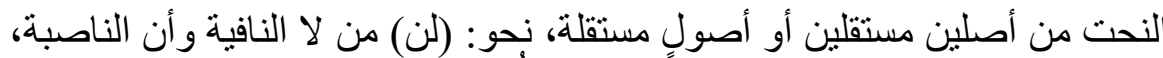

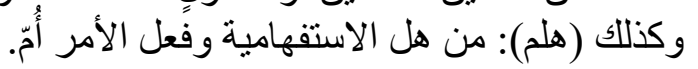

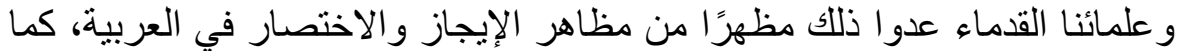

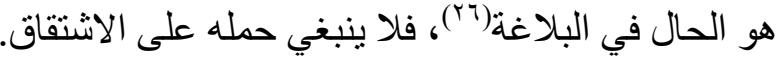

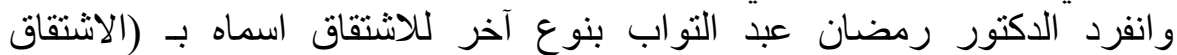

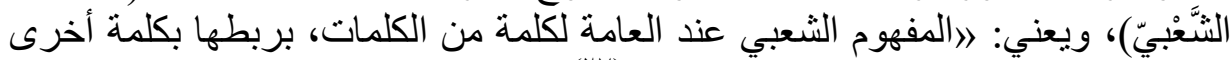

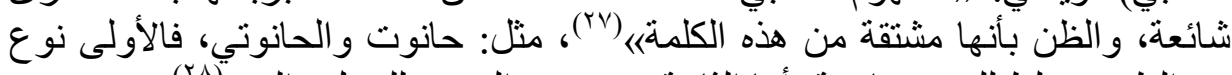

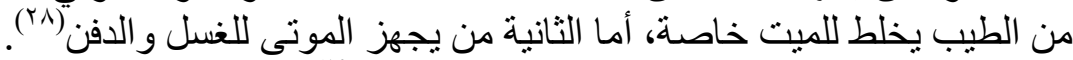

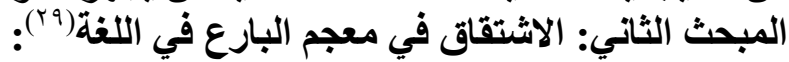

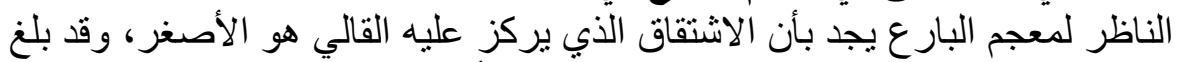

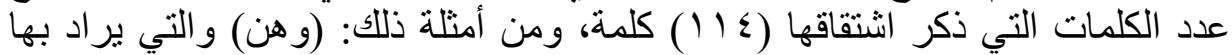

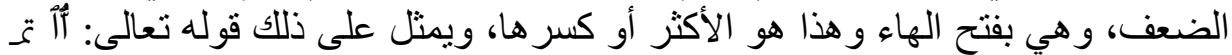

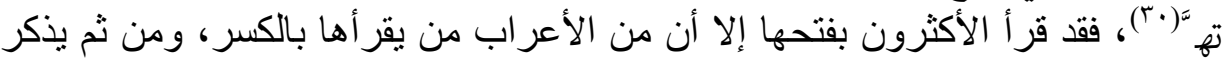

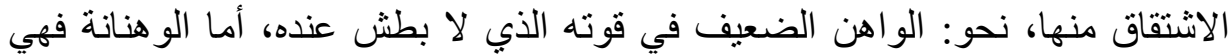

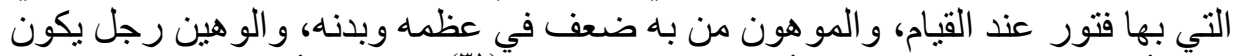

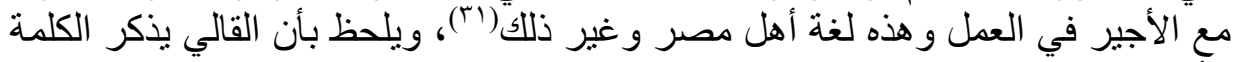

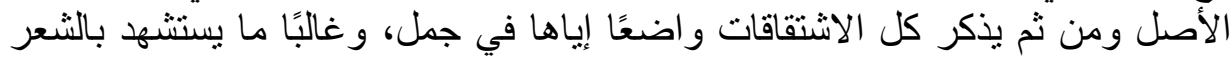

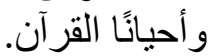

وكما نجد القالي أكثر من ذكر الانتقاق الكبير، وقد بلغ عدد الكلمات التي ذكر التهر

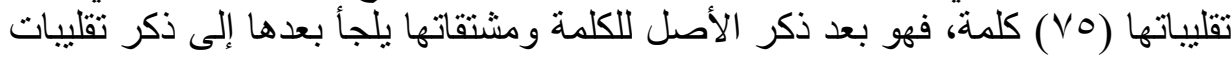

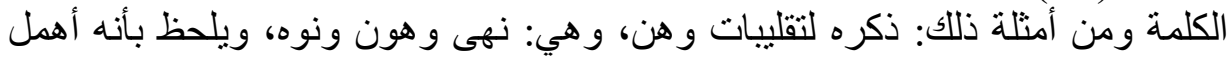

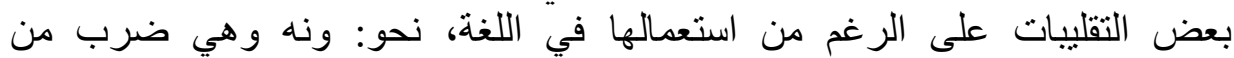

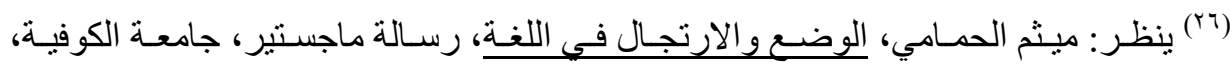
. $\wedge \varepsilon ،(م) 99 \Lambda)$

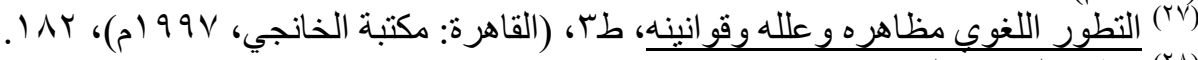
(بی)

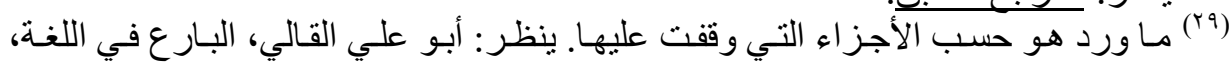

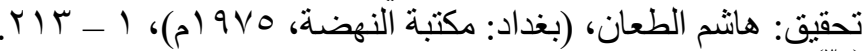
(ال)

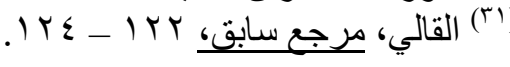


الأوتار (rT)، كما أنه لم يرجع هذه التقليبات لمعنى جامع مشترك، بل يكتفي بذكر المعنى

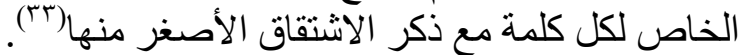

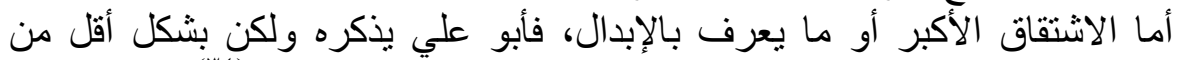

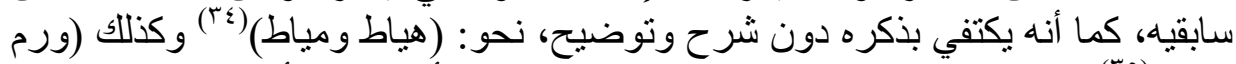

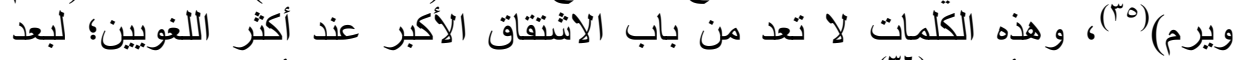

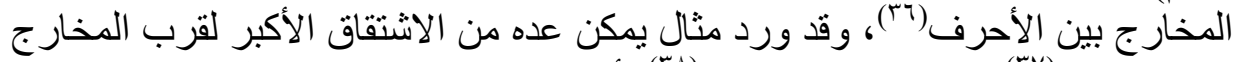

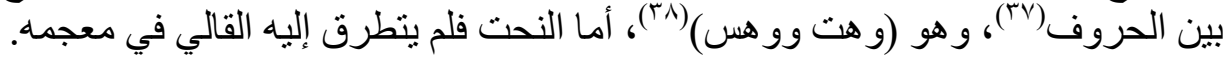

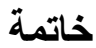

بعد حمد الله الذي يسر إتمام هذا العمل، وبعد تناول تعريف الاشتقاق وأنواعه: إعه: دراسة

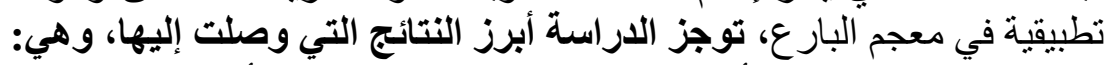

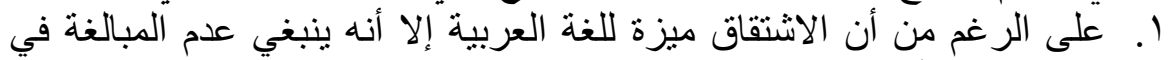

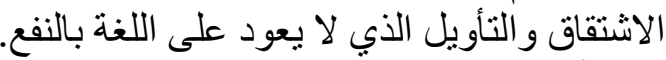

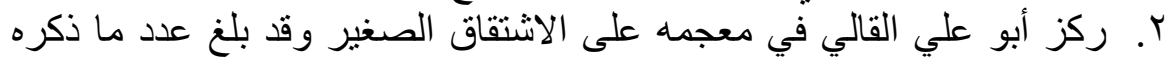
( بع (1)

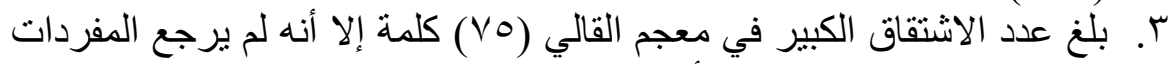

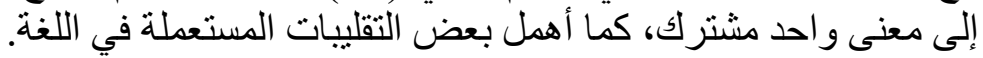

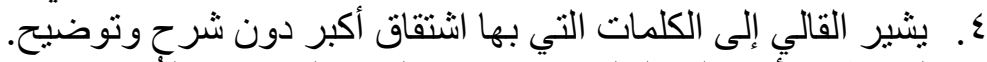

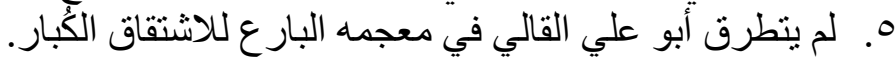
وآخر دعوانا أن الحمد لله رب ألعالمين، وصلى الله وسلم على نبي المرسلين.

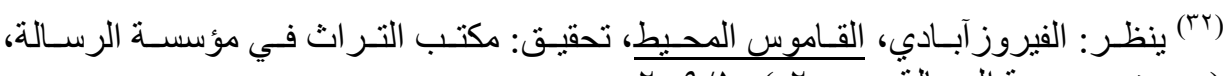

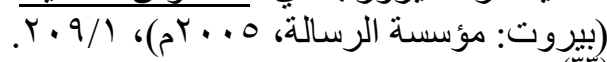
(بr)

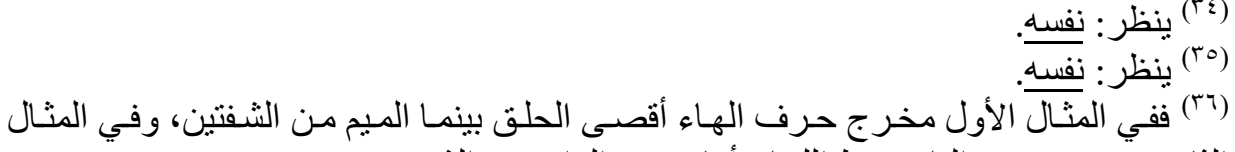
الثاني مخرج حرف الياء وسط اللسان أما حرف الو الو او فمن الثفنتين.

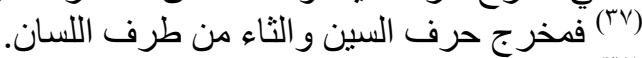
$1 \leqslant V$ إنظ 


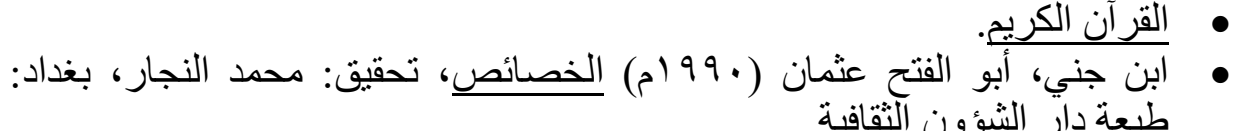

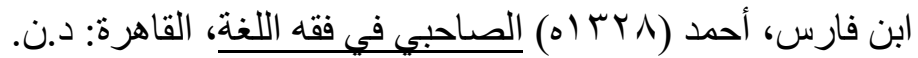

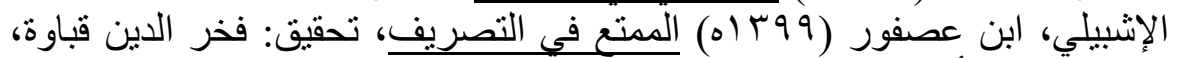

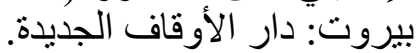

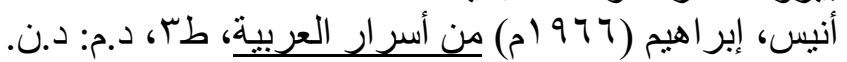

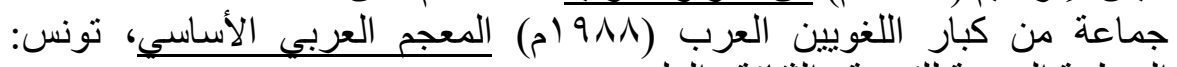

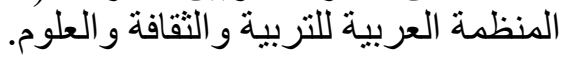

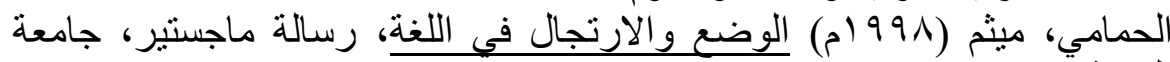
الكوفة. خان، محمد صديق ( \9 Y (ه) العلم الخفاق من علم الاشتقاق، القسطنطينية: مطبعة

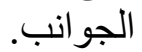
الروماني، أبو الحسن (1997 (م) الحدود في النحو، تحقيق: مصطفى جواد ويوسف مسكوني، بغداد: دار الجمهورية. السراج، أبو بكر (9VT (م) الاشتقاق، تحقيق محمد التكريتي، بغداد: مكتبة المعارف. السيوطي، جلال الدين (د.ت) المزهر هري في علوم اللغة و أنو اعها، تحقيق: جاد المولى محمد البجاوب، هيروت الاين: دار الفكر.

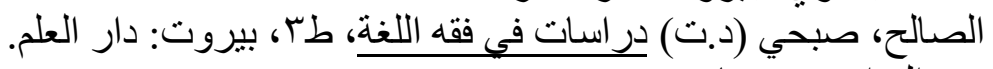
عبد التواب، رمضان:

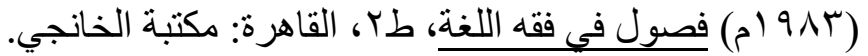
(99V)

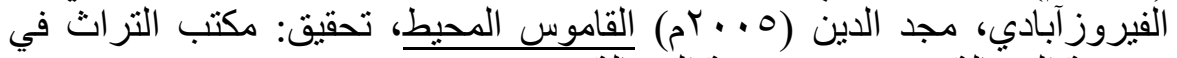

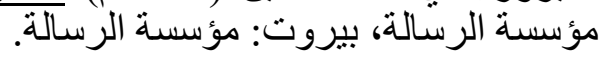

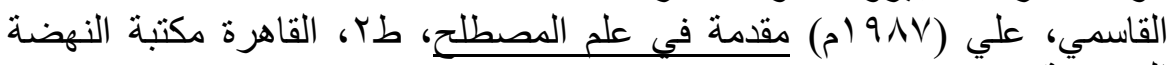
المصريّة. القالي، أبو علي (9V0) البح) البارع في اللغة، تحقيق: هاشم الطعان، بغداد: مكتبة النهضية. المبارك، عبد الحسين (7^ه (م) فقه اللغة، البصرة: مطبعة جامعة البصرة. 
• مسدي، عبد السلام (ع 9 (1م) قاموس اللسانيات، نونس: الدار العربية للكتاب.

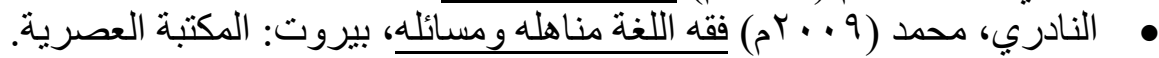

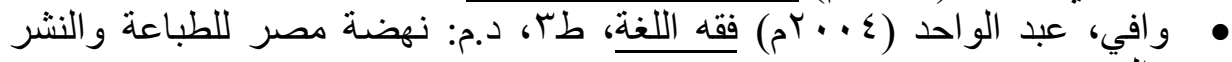
و التوزيع. 
